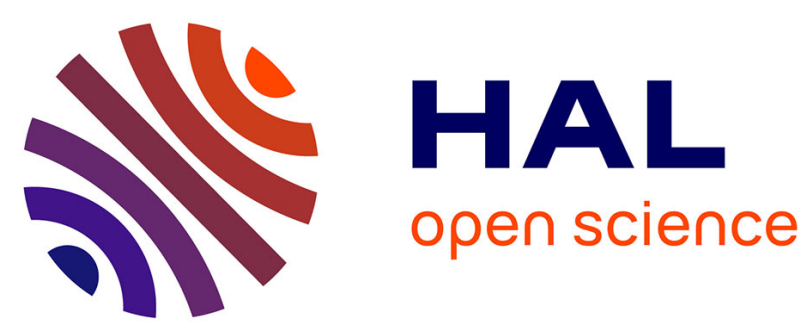

\title{
Effect of heat exposure and exercise on food intake regulation: a randomized crossover study in young healthy men
}

Cécile Faure, Keyne Charlot, Stéphane Henri, Marie-Dominique Hardy-Dessources, Olivier Hue, Sophie Antoine-Jonville

\section{To cite this version:}

Cécile Faure, Keyne Charlot, Stéphane Henri, Marie-Dominique Hardy-Dessources, Olivier Hue, et al. Effect of heat exposure and exercise on food intake regulation: a randomized crossover study in young healthy men. Metabolism, 2016, 65 (10), pp.1541-1549. 10.1016/j.metabol.2016.07.004 . hal-01496661

\section{HAL Id: hal-01496661 https://hal.science/hal-01496661}

Submitted on 27 Mar 2017

HAL is a multi-disciplinary open access archive for the deposit and dissemination of scientific research documents, whether they are published or not. The documents may come from teaching and research institutions in France or abroad, or from public or private research centers.
L'archive ouverte pluridisciplinaire HAL, est destinée au dépôt et à la diffusion de documents scientifiques de niveau recherche, publiés ou non, émanant des établissements d'enseignement et de recherche français ou étrangers, des laboratoires publics ou privés. 
1 Effect of heat exposure and exercise on food intake regulation: a

8 a Adaptation to Tropical Climate, Exercise and Health Laboratory, EA3596, University of the

9 French West Indies, Pointe-à-Pitre, Guadeloupe, France

$10 \quad{ }^{\mathrm{b}}$ UMR Inserm 1134, University of the French West Indies, Guadeloupe

$11{ }^{c}$ France-Laboratory of Excellence GR-Ex (The red cell: from genesis to death), PRES 12 Sorbonne Paris Cité, Paris, France

$13 \mathrm{~d}$ Orthopedics and Trauma Center, Academic Hospital of Pointe-à-Pitre-Abymes, 14 Guadeloupe, France

17 Corresponding author:

18 Dr. Sophie Antoine-Jonville

19 Laboratoire ACTES, Université des Antilles et de la Guyane

20 BP 250

2197157 POINTE A PITRE Cédex

22 GUADELOUPE

$23 \quad$ s_antoine@ymail.com_sophie.jonville@univ-ag.fr

24 Tel: (+590) 590483175 Fax: (+ 590) 590483179

27 Disclosures: The authors declare no conflict of interest. 


\section{ABSTRACT}

\section{Objective}

30 The effect of physical activity on food intake regulation may be moderated by environmental

31 temperature. The aim of the study was to determine the single and combined effects of

32 metabolic activity and temperature on energy intake and its hormonal regulation.

33 Methods

34 A randomized crossover study was conducted in the laboratory. Ten healthy and physically active young Afro-Caribbean men participated in four experimental sessions (rest at $22^{\circ} \mathrm{C}$ and $31^{\circ} \mathrm{C}$ and cycling at $60 \%$ of their maximal oxygen uptake at $22^{\circ} \mathrm{C}$ and $31^{\circ} \mathrm{C}$, all for 40 minutes). Each test period was followed by a 30-minute recovery period and then an ad libitum meal. The main outcome measures were energy balance, subjective appetite, and plasma pancreatic polypeptide (PP), cholecystokinin (CCK) and ghrelin concentrations.

\section{Results}

41 Relative energy intake was significantly decreased whereas plasma PP was increased in the exercise conditions ( $p=0.004$ and $p=0.002$, respectively). Postprandial levels of CCK were elevated only in the rest conditions. Exposure to heat induced a decrease in plasma ghrelin

$44 \quad(p=0.031)$.

\section{Conclusions}

46 Exercise induced a short-term energy deficit. However, modifications in the hormonal

47 regulation of food intake in response to short-term heat or heat and exercise exposure seem to

48 be minor and did not induce changes in energy intake.

49 This trial was registered at clinicaltrials.gov as NCT02157233.

51 Abbreviations. PP: pancreatic polypeptide; CCK: cholecystokinin; rest $-22^{\circ} \mathrm{C}$ : rest at $22^{\circ} \mathrm{C}$;

52 rest- $31^{\circ} \mathrm{C}$; rest at $31^{\circ} \mathrm{C}$; ex $-22^{\circ} \mathrm{C}$ : exercise at $22^{\circ} \mathrm{C}$; ex $-31^{\circ} \mathrm{C}$ : exercise at $31^{\circ} \mathrm{C}$; $\mathrm{VO}_{2 \max }$ : 
53 maximal oxygen uptake

54

55 Key words. Physical activity; Food intake regulation; Environment; Energy balance;

56 Metabolism 


\section{INTRODUCTION}

58 Overweight and obesity have reached epidemic proportions throughout the world and are now

59 the fifth leading risk for death worldwide [1]. The prevalence of their associated

60 comorbidities has also risen, further increasing the healthcare costs [2]. A better

61 understanding of the underlying mechanisms, starting with studies on healthy individuals, is

62 crucial for the development of strategies to manage this epidemic. Along with genetic,

63 physiological and behavioral factors, a fundamental cause of overweight and obesity is an

64 imbalance between energy intake and expenditure. Mounting evidence suggests that the

65 increased intake of energy-dense foods and the decrease in physical activity due to

66 increasingly sedentary lifestyles are the main explanations for this imbalance [2].

67 The general mechanisms of energy balance regulation are well known, with most data coming

68 from studies performed in temperate climates. The mechanisms rely mainly on the integration

69 of signals that reflect the metabolic state of peripheral tissues. These signals are either

70 orexigenic, like ghrelin, or anorexigenic, like pancreatic polypeptide (PP), cholecystokinin

71 (CCK) or peptide YY [3]. The mechanisms of short-term post-exercise food intake regulation

72 have been particularly informative. An increase in the secretion of anorexigenic factors and an

73 inhibition of ghrelin secretion, which is orexigenic, have been described in subjects after they

74 perform an acute exercise bout [4] or in response to overfeeding plus exercise [5]. These

75 mechanisms contribute to a relative food intake inhibition (energy intake after accounting for

76 the extra energy expended during the exercise), while an acute exercise bout has no

77 meaningful effect on the subsequent absolute energy intake [6].

78 The effect of physical activity on energy intake is moderated by other factors, as well,

79 including exercise intensity and duration, training status, sex, amount of body fat [6,7].

80 Among these factors, environmental temperature in which the exercise task is performed has 
81 not been extensively studied. However, further investigation on this factor is relevant for the

82 understanding of energy intake behaviors. Based on the perturbations of human [8,9] and

83 animal [10] feeding behaviors reported in hot environment, we hypothesized that heat and

84 exercise would interact to reduce relative energy intake. The aim of the study was thus to

85 determine the single and combined effects of metabolic activity and environmental

86 temperature on energy intake and its hormonal regulation.

\section{SUBJECTS AND METHODS}

\subsection{Ethical approval}

89 This trial was registered at clinicaltrials.gov as NCT02157233 and approved by the Regional

90 Ethics Committee (French Human Subject Review Committee of Limoges, France: CPP1391 018a/2013-A01037-38). The experiments were performed in accordance with the guidelines

92 set by the Declaration of Helsinki and written informed consents to participate in the study 93 were obtained from all subjects. The study sponsors were not involved in study design, 94 collection and analysis of data, writing the report or the decision to submit the manuscript for 95 publication.

\subsection{Subjects}

97 Participants were recruited from October 2013 to November 2014 by the research manager.

98 Advertisements posted on the University of the French West Indies Guadeloupian campus and 99 in surrounding sports centers were used.

100 Ten healthy and physically active men (age: $20.7 \pm 1.7 \mathrm{yrs}$, height: $1.80 \pm 0.06 \mathrm{~m}$, body mass: $10169.2 \pm 7.1 \mathrm{~kg}$, body mass index: $21.3 \pm 1.7 \mathrm{~kg} \cdot \mathrm{m}^{-2}$, fat mass: $7.2 \pm 5.3 \%$ ) were included in the study. They were all of Afro-Caribbean origin. 
103 Subjects had stable body mass ( $\pm 2 \mathrm{~kg}$ for more than 1 year, determined by self-report). They

104 were nonsmokers, without major chronic disease (i.e., diabetes, coronary heart disease), and

105 not taking medications known to influence food intake or body mass. They reported normal

106 body mass at birth and were born at term. They had lived in the Caribbean area for more than

1073 months and were thus well acclimated to a tropical climate. They reported no food allergies

108 or restrictions and screening had excluded individuals with eating disorders [11]. They trained

109 regularly with a mixture of endurance and resistance exercises. Their physical activity was

110 within a range of 2000-6000 METs.min/week (2100-6700 kcal/week). The subjects were not

111 aware of the specific purpose of the study.

\section{2.3. Experimental design}

113 The subjects underwent a familiarization and testing session, during which their maximal

114 oxygen uptake $\left(\dot{\mathrm{V}} \mathrm{O}_{2 \max }\right)$ and anthropometric data were measured. They then participated in

115 the experimental trials, which were administered in a randomized counterbalanced design

116 over 4 days: a resting control in a neutral environmental temperature (rest- $22^{\circ} \mathrm{C}$ ), a resting

117 control in a hot temperature (rest- $31^{\circ} \mathrm{C}$ ), exercise (cycling) in a neutral environmental

118 temperature $\left(\mathrm{ex}-22^{\circ} \mathrm{C}\right)$ and exercise in a hot temperature $\left(\mathrm{ex}-31^{\circ} \mathrm{C}\right)$. They were instructed to

119 have similar energy intake and to abstain from high-intensity exercise and alcohol the day

120 before each session. This was carefully checked with food and activity journals. Sessions

121 would be postponed in case of unacceptable quality or quantity dissimilarity. Subjects

122 reported to the laboratory at 6:30 am after an overnight fast on four occasions at least one

123 week apart.

124 The experiment was divided into three parts (Fig. 1): the "test" of 40 minutes in either the rest 125 or the exercise condition, followed by a 30-minute rest period, and then an ad libitum meal of 12630 minutes. During the control trials, the subjects lay on an examination table for 40 minutes. 
127 The exercise trials consisted of a 40 minutes cycling (Monark Weight Ergometer 814 E,

128 Varberg, Sweden) at $60 \%$ of their $\mathrm{VO}_{2 \max }$. The environmental temperatures were set at $22^{\circ} \mathrm{C}$

129 and $31^{\circ} \mathrm{C}$ for neutral and hot temperature, respectively, with $45 \%$ relative humidity, and stable

130 temperature and humidity throughout each session.

131 Hydration was controlled during the entire study, as follows. During the 40-minute test

132 period, the subjects were given $200 \mathrm{ml}$ of water when they were resting and $400 \mathrm{ml}$ of water 133 when exercising, and they could drink as much as they wanted to. At T40, they were weighed

134 and given water in an amount equal to that of the loss in body mass, to compensate the water

135 loss. The water absorbed during the recovery period to compensate water loss was recorded.

136 During the ad libitum meal at the end of sessions, they had a quantity of water corresponding

137 to $4 \mathrm{ml}$ water $/ \mathrm{kg}$ body mass.

\subsection{Anthropometric data}

\subsubsection{Body mass, height and body mass index (BMI)}

140 Body mass was measured without clothing, once before the test (physical activity or resting 141 control) and once after, to determine mass loss due to sweating. Prior to bioelectric impedance 142 analysis, height was measured to the nearest $0.1 \mathrm{~cm}$ using a wall-mounted stadiometer. BMI 143 was then calculated.

\subsubsection{Bioelectric impedance analysis}

145 The subjects underwent bioelectric impedance analysis, using an InBody S10 body 146 composition analyzer with InBody 3.0 software (BioSpace) to determine their body fat mass.

147 They lay supine and body mass and height were input into the analyzer. This instrument uses 148 eight tactile electrodes, two of which are in contact with the thumb and middle finger of each 149 hand, and two in contact with the bilateral aspects of the ankle joint of each foot. 


\subsection{Cardiopulmonary assessment}

151 On their first visit to the laboratory, the subjects' $\mathrm{VO}_{2 \max }$ was measured with an incremental 152 exercise test to exhaustion, performed on a cycle ergometer (Monark Weight Ergometer 153 814E, Varberg, Sweden). The increments were set at $15-20 \mathrm{~W}$ per minute according to the 154 expected physical fitness so as to reach exhaustion within 12 minutes as recommended [12].

155 Complete metabolic data were collected using a breath-by-breath ergospirometry system 156 (Metalyzer ${ }^{\circledR} 3 \mathrm{~B}$, Cortex Biophysik GmbH, Germany). They had a $\mathrm{VO}_{2 \max }$ of $47.1 \pm 7.4$ $157 \quad \mathrm{ml} \cdot \mathrm{min}^{-1} \cdot \mathrm{kg}^{-1}$.

158 During the four experimental sessions, heart rate (PolarVantage, Polar Electro Oy, Kempele, 159 Finland), oxygen consumption and respiratory exchange ratio (RER) (Metalyzer ${ }^{\circledR} 3 \mathrm{~B}$, Cortex 160 Biophysik GmbH, Germany) were assessed regularly (Fig. 1).

\section{$161 \quad$ 2.6. Core temperature and thermal comfort}

162 The tympanic membrane is supplied with blood from the internal carotid artery just like the 163 hypothalamus. This cranial location thus served as a substitute for the measurement of the 164 inaccessible hypothalamic temperature [13].

165 Core temperature was recorded during the tests with a tympanic temperature probe (Smiths

166 Medical, St Paul, MN, USA) placed in the aural canal near the tympanic membrane. The 167 tympanic probe was held in position and isolated from the external environment with cotton, 168 surgical tape (Transpore; 3M, London, Ontario, Canada), and an ear defender (model 1000; 169 Mastercraft, Bobcaygeon, Ontario, Canada) as described by others [14].

170 Subjects were asked to assess their thermal comfort using a visual analog scale (VAS). 


\subsection{Energy balance}

\subsubsection{Energy expenditure}

174 Energy expended during the tests was determined by indirect calorimetry (Metalyzer ${ }^{\circledR} 3 \mathrm{~B}$,

175 Cortex Biophysik GmbH, Leipzig, Germany) and calculated using the Weir equation.

\subsubsection{Assessment of energy intake}

177 Prior to the study, individuals who were eligible for study inclusion were asked to describe

178 what they usually ate for breakfast. Test meal items were evaluated for palatability before

179 initiation of the study. We thus tried to offer the subjects familiar foods for breakfast in order

180 to be as close as possible to the real-life meal situation. Indeed, Blundell et al. reported that

181 this procedure results in a better assessment of energy intake [15].

182 Forty minutes after each experimental trial, the subjects were thus presented with an array of

183 ham and cheese sandwiches of known energy composition $(327 \mathrm{kcal} / 100 \mathrm{~g}$, according to the

184 French food composition table [16]) for 30 minutes, during which time they were instructed

185 to eat ad libitum until satiety was reached. The foods provided were in excess of the expected 186 intakes.

187 Total energy intake from the breakfast meal was calculated by weighing all remaining food 188 products after the participant had left the laboratory. This method has been shown to be 189 reliable for assessing energy intake [17]. Total kilocalories were recorded. In addition, relative 190 energy intake was calculated by correcting post-exercise energy intake for the energy cost of

191 the exercise session as follows: Rel EI = EI - EE, where Rel EI is the relative energy intake,

192 EI is the absolute energy intake during the ad libitum meal, and EE is the energy expenditure 193 during the 40-minute test period. 


\subsection{Subjective appetite sensations}

195 A VAS was used to measure subjective appetite sensations. Subjects were asked to rate their 196 hunger (How hungry do you feel? "not hungry at all" to "as hungry as I've ever felt"), desire 197 to eat (How strong is your desire to eat?: "very weak" to "very strong"), fullness (How full do 198 you feel? "not full at all" to "very full"), and prospective food consumption (How much do 199 you think you can eat? "nothing at all" to "a large amount"). The composite appetite score 200 (CAS) reflects the responses to the four VAS questions and was included in the study as a 201 summary measure of appetite. CAS was calculated using the following formula: CAS $=((100$ $202-$ satiety $)+(100-$ fullness $)+$ desire to eat + prospective food intake $) / 4$ [18].

\subsection{Hormones involved in food intake regulation}

204 Upon arrival, a catheter was inserted into an antecubital vein for blood sampling. Venous 205 blood was drawn into Vacutainer tubes containing EDTA before, during, and after 206 rest/exercise and in the postprandial state. The blood was transferred from the Vacutainer 207 tubes to centrifuge tubes containing aprotinin $(0.6 \mathrm{TIU} / \mathrm{ml}$ of blood $)$ and gently rocked several 208 times to inhibit the activity of proteinases. After centrifugation at $1,600 \mathrm{xg}$ for 15 minutes at $4^{\circ} \mathrm{C}$, 209 the plasma was collected and kept at $-70^{\circ} \mathrm{C}$ until analysis. Plasma PP, CCK and ghrelin 210 concentrations were measured from these samples, using Enzyme Immunoassay kits and

211 according to the manufacturer's protocols (Phoenix Pharmaceuticals, Inc., Burlingame, CA, 212 USA).

\section{$213 \quad$ 2.10. Statistics}

214 The required number of participants was a priori calculated using $\mathrm{G}^{*}$ power 3.1 for Mac. 215 Alpha error probability threshold was 0.05 . The calculations were performed based on expected relative energy intake, with different effect size and different power between 0.80 
217 and 0.95 , and 0.85 for correspondence among repeated measures. Resulting required sample

218 size varied. Ten appeared as feasible and sufficient to evidence an effect size of 0.4 , with 0.80

219 power. All results were analyzed with the SPSS v.20 software package (SPSS Inc., Chicago,

220 IL, USA). A probability value of $\mathrm{p}<0.05$ was considered statistically significant. Data are

221 presented as means \pm SDs except in figures where SEMs are used.

222 Three-factor repeated-measures analyses of variance were performed to analyze the effects of 223 metabolic activity (2 levels: rest and exercise), ambient temperature (2 levels: neutral and 224 hot), time (4, 6 or 8 levels), and their interaction on plasma hormone concentrations, tympanic 225 temperature, thermal comfort, composite appetite sensations and cardiopulmonary data.

226 Two-factor repeated-measures analyses of variance were performed to analyze the effects of 227 metabolic activity, ambient temperature and their interaction on energy expenditure, absolute 228 energy intake, relative energy intake and water intake.

229 Data were tested for sphericity using Mauchly's test and if the assumption of sphericity was 230 violated, the Greenhouse-Geisser correction was undertaken to adjust the degrees of freedom. 231 Tukey's post-hoc tests were performed to identify mean differences among conditions when 232 the effect of time $\mathrm{x}$ metabolic activity, time $\mathrm{x}$ temperature, or time $\mathrm{x}$ temperature $\mathrm{x}$ metabolic 233 activity was significant. Otherwise, only significant simple effects or interaction effects are 234 reported.

\section{3. RESULTS}

236 3.1. Cardiopulmonary assessment (Fig. 2)

237 Oxygen uptake and RER (Fig. 2a and 2c) were affected by the metabolic activity, time and 238 their interaction $(\mathrm{p}<0.001)$. Heart rate (Fig. $2 b)$ was significantly increased in the exercise 239 conditions $(p<0.001)$. It was also higher in the hot conditions than in the neutral ones 
$240(p=0.003)$. There was an effect of time $(p<0.001)$ on heart rate, and the interaction of

241 metabolic activity $\mathrm{x}$ temperature $\mathrm{x}$ time was significant $(\mathrm{p}<0.043)$.

\section{$242 \quad 3.2$. Temperature and thermal comfort}

243 The variation from T0 tympanic temperature was significantly affected by the interaction of

244 metabolic activity $\mathrm{x}$ temperature $\mathrm{x}$ time was significant $(\mathrm{p}=0.001)$, exclusively due to higher

245 values at all times in the Ex $-31^{\circ} \mathrm{C}$ session as compared to the others (all $\left.\mathrm{p}<0.001\right)$. Metabolic

246 activity, time, temperature and their interactions significantly affected thermal comfort (Fig.

247 3), except for the metabolic activity $\mathrm{x}$ temperature $\mathrm{x}$ time interaction, which was not 248 significant.

\section{$249 \quad$ 3.3. Water intake}

250 Water intakes during the 40-min test, water intakes to compensate water loss and during the 251 meal and total water intakes are reported in table 1. Exercise increased water intake during the 25240 -minute test period $(\mathrm{p}<0.001)$ and during the recovery to compensate water loss $(\mathrm{p}=0.002)$, 253 as well as the total water intake $(\mathrm{p}<0.001)$. Water intake during the 40 -minute test period and 254 total water intake were also affected by temperature $(p<0.001$ and $p=0.019$, respectively). The 255 combined effects of metabolic activity and temperature on total water intake approached 256 significance $(\mathrm{p}=0.072)$.

\section{3.4. Energy balance and appetite}

258 The energy expended during the 40-minute test periods was $45 \pm 6,46 \pm 6,389 \pm 22$ and 385 $259 \pm 26 \mathrm{kcal}$, in the rest $-22^{\circ} \mathrm{C}$, rest $-31^{\circ} \mathrm{C}$, ex $-22^{\circ} \mathrm{C}$ and ex $-31^{\circ} \mathrm{C}$ conditions, respectively. It was 260 only affected by metabolic activity $(\mathrm{p}<0.001)$. Absolute energy intake did not differ between 261 the four experimental conditions $(1042 \pm 330,1039 \pm 217,1156 \pm 236$ and $1090 \pm 296 \mathrm{kcal}$ in 
262 the rest $-22^{\circ} \mathrm{C}$, rest $-31^{\circ} \mathrm{C}$, ex $-22^{\circ} \mathrm{C}$ and ex $-31^{\circ} \mathrm{C}$ conditions, respectively), neither was energy

263 intake reported to body mass (all $\mathrm{p}>0.258$ for metabolic activity, temperature and interaction).

264 The relative energy intake (Fig. 4) was significantly decreased in the exercise conditions

265 compared with the rest conditions $(\mathrm{p}=0.004)$.

266 The composite appetite sensation (Fig. 5) was only affected by time $(p<0.001)$. The effect of 267 temperature did not reach significance $(\mathrm{p}=0.073)$, with a trend towards reduced appetite in the 268 hot conditions.

\section{3.5. Markers of food intake regulation}

270 Plasma PP (Fig. 6) was increased in the exercise conditions $(\mathrm{p}=0.002)$ compared with rest 271 conditions. It was also affected by time $(\mathrm{p}<0.001)$, with postprandial PP being higher than at 272 all other time points.

273 CCK (Fig. 7) was affected by time ( $p=0.005)$, with a significant increase at T100 compared 274 with T40 and T55 ( $\mathrm{p}=0.006$ and 0.002 , respectively). The metabolic activity $\mathrm{x}$ time interaction 275 was also significant $(\mathrm{p}=0.005)$.

276 The meal induced an increase in CCK only in the rest conditions ( $p=0.006$ and $p<0.001$ for 277 rest- $22^{\circ} \mathrm{C}$ and rest- $31^{\circ} \mathrm{C}$, respectively). In the rest- $31^{\circ} \mathrm{C}$ condition, postprandial CCK was 278 higher than at all other time points $(\mathrm{p}<0.001)$.

279 Plasma ghrelin (Fig. 8) was affected by the environmental temperature, with higher levels in 280 the neutral conditions $(\mathrm{p}=0.031)$. 


\section{DISCUSSION}

284 The main findings of this first randomized crossover study including rest and exercise in

285 neutral and hot ambient temperatures and focused on energy balance regulation were: 1)

286 exercise induces a decrease in the relative energy intake; 2) heat does not further modify this

287 effect in these acclimated subjects; 3) CCK and PP were differently affected by the metabolic

288 activity, while ghrelin was decreased in the heat.

289 A suppressive effect of exercise on appetite, referred to as short-term exercise-induced 290 anorexia, has been described [19]. The anorexic effect of exercise is more likely to be 291 observed in obese/overweight or sedentary individuals. Highly fit and physically active 292 people do not exhibit the same response to exercise [6,20,21]. Our findings confirm the 293 general observation that absolute energy intake is not affected by metabolic activity, although 294 this observation is not unanimous.

295 Nevertheless, the increase in energy expenditure caused by increased metabolic activity was 296 not compensated for by increased energy intake. A few studies have reported that increased 297 energy requirements do not always immediately trigger increased energy intake and appetite 298 and, consequently, exercise is likely to induce negative energy balance [6]. The cause of this 299 exercise-induced energy deficit is not precisely known but several mechanisms have been 300 proposed. They include the improvement of satiety by increasing the postprandial sensitivity 301 to ingested nutrients consumed in post-exercise meals [22].

302 Such an energy deficit, if repeated over a longer period, could have significant implications in 303 terms of weight management. The question can also be analyzed from the point of view of the 304 resting sessions, which are likely to induce positive energy balance on longer term. This study 305 fuels the idea of an inability to compensate for inactivity by reducing energy intake [22]. 
306 Contrary to our hypothesis, the environmental temperature did not seem to modify the energy

307 intake subsequent to exercise in these acclimated subjects. Similarly to what we observed, a

308 previous study reported no difference in absolute and relative energy intake after exercise

309 performed in the heat and a neutral environment [8].

310 Given its randomized crossover design, this study could investigate the mechanisms of energy

311 balance after exercise in the heat. The focus on CCK and PP was motivated by the putative 312 theoretical impact of heat exposure on gastro-intestinal tract releases due to blood flow 313 redistribution. We observed an elevation of these anorexigenic factors (i.e., CCK and PP) in 314 response to food intake, as expected [23,24]. Total ghrelin levels known as an orexigenic 315 factor, however, were not affected by food intake. Similar observations were reported, with 316 no modification in ghrelin levels 30 minutes after the ingestion of a meal, following rest or 317 exercise [25]. Although there is a close relationship between total and the biologically active 318 appetite stimulating acylated ghrelin it can not be excluded that after exercise and/or exposure 319 to heat this relationship is somewhat different.

320 We found small effects of exercise on the appetite hormone levels, as reported in other studies 321 [4]. CCK and PP, the two anorexigenic factors measured in our study, seem to be differently 322 affected by metabolic activity. Whereas PP was higher in the exercise conditions, CCK 323 increased only after food intake in the rest conditions. The increased secretion of PP in the 324 exercise conditions is in accordance with a recent meta-analysis [6]. This is very compatible 325 with previous observations reporting that not only does acute exercise increase fasting plasma 326 PP [26], but it also raises postprandial PP levels [27].

327 Unlike for PP, very few data are available on the effects of acute exercise on CCK. 328 Observations partly contrary to our finding have been reported, with one study suggesting that 329 acute exercise increased plasma CCK levels [28]. The main reason for this discrepancy stands 
330 probably in the differences of intensity and duration. The study by Bailey et al. involves

331 maximal incremental exercise performed in less than 20 minutes, which generates metabolic

332 stimuli not comparable to the ones raised by our exercise conditions. Our results are similar to

333 the findings for chronic exercise, with stable levels of CCK [28] while those of PP are

334 increased [29]. Moreover, one study reported that CCK levels were reduced in response to

335 food intake in women athletes, as compared with sedentary controls, when energy intake was 336 increased [30]. This could be paralleled to the reduced levels of postprandial CCK after 337 exercising, and suggests that energy expenditure may modify the CCK response to food 338 intake. We are not aware of investigations on CCK in response to exercise in the heat. To our 339 knowledge, we are the first to provide evidence that hot environmental temperature does not 340 further modify the effect of exercise on CCK levels. This would mean that despite probable 341 different blood flow in the gastro-intestinal tract, CCK release would be preserved. CCK then 342 appears as a robust anorexigenic factor maintaining its function whatever the ambient 343 temperature variation (within the range we tested here). Also, this discards the 344 thermoregulatory mechanisms as the main triggers of CCK inhibition in response to exercise.

345 Metabolic activity did not affect plasma ghrelin, however, as evidenced earlier by other 346 studies in healthy subjects [31-33]. Indeed, total plasma ghrelin levels were not modified after 347 high-intensity exercise [25], but a few data support the idea that an acute bout of exercise 348 influences appetite by suppressing levels of acylated ghrelin [4]. Desacyl ghrelin (not 349 measured in our study), in contrast to acylated ghrelin, induces a negative energy balance by 350 decreasing food intake [34]. This may have contributed to the post-exercise energy deficit 351 observed in our study.

352 Ghrelin levels were affected by the environmental temperature, whereas temperature had no 353 effect on the plasma levels of CCK or PP. This agrees with recent findings that the 
354 hypothalamic mRNA levels of CCK were not modified after heat exposure in chickens [35].

355 As the outside temperature in Guadeloupe is about $28^{\circ} \mathrm{C}$ with $80 \%$ relative humidity (day and

356 night average), the subjects underwent cold exposure when they entered the $22^{\circ} \mathrm{C}$ room, as

357 was reflected by their reports of lower thermal comfort in the $22^{\circ} \mathrm{C}$ conditions, even at

358 baseline. Since acute exposure to cold increases plasma ghrelin levels [36], acclimation of our

359 participants to tropical climate may explain the higher ghrelin level at baseline and all through

360 the session, even though not significantly so at single time points, in the $22^{\circ} \mathrm{C}$ condition.

361 Apart from this specific initial response, our data basically confirm some of those recently

362 published by Kojima et al. [37] whereas disagreements can be explained by differences in

363 fitness of the participants. They also provide suspicions that acclimation is a potential

364 modulator factor, and that ghrelin is a fast and sensitive responder to relative cold exposure.

365 One of the strengths of this study resides in its design. To the best of our knowledge, this is 366 the first study with subjects who participated in both rest and exercise sessions, in neutral and

367 hot ambient temperatures. Moreover, water intake was carefully controlled, unlike most of the 368 studies investigating food intake and its regulation. The role of water intake in decreased

369 hunger and food intake has not been extensively studied. A few studies have reported that 370 water consumed before and during a meal does not modify energy intake in young subjects $371[38,39]$, and a recent one showed that hydration status had no impact on post-exercise appetite 372 or energy intake [40]. In older and obese older adults, however, water consumption reduces 373 energy intake [38]. As the results seem to differ depending on the situation and the population 374 under study, and given that both exercise and heat induce water loss, we chose an 375 experimental design that controlled for hydration status to avoid any potential bias.

376 The limitations of this study are its very acute nature, the lack of inclusion of women, the 377 small number of subjects and the low values for body fat mass, the latter two of which impede 
378 generalization to overweight or obese populations. Moreover, as water intake was controlled, 379 the subjects of our study seem to have drunk less water than in a previous study [8], and this 380 may not actually reflect what would have occurred in real life. Last, conversely to most 381 studies, the subjects involved in the experiment were acclimated to heat, which makes 382 comparisons difficult.

383 In conclusion, exercise induced a short-term energy deficit. However, modifications in the 384 hormonal regulation of food intake in response to short-term exposures to heat or to heat and 385 exercise seem to be minor and did not induce any changes in energy intake. Long-term studies 386 are required to comprehend the role of environmental temperature among the modulators for 387 energy balance. This would allow a better understanding of the association between exercise 388 training and performance, and body mass regulation in tropical and hot environments. 389 Overweight individuals would also be an interesting target for further studies. Since this 390 population seems to present specific patterns of response to environmental temperature [41], 391 further studies should also be conducted on less fit and lean subjects to apprehend whether 392 similar conclusions would apply to physical activity interventions for people involved in 393 weight management programs. 
394 ACKNOWLEDGEMENTS. We warmly thank the subjects and the nurse and physician 395 (Véronique Conord and Thibault Philippe) for their great involvement. The authors also thank 396 Cathy Carmeni for her excellent revision and suggestions. SAJ expresses her warm thanks to 397 Pr. Anderson's team at the Department of Nutritional Sciences and Physiology for inspiring 398 this research project.

400 FUNDING. This project was supported by grants from the European Social Fund and Region

401 Guadeloupe (No CR/12-116), the French Ministry of Overseas Territories (No 0123-C001402 D971/2013), and the European Regional Development Fund (PO No 1/1.4/-31793).

403 The funders had no role in the study design, data collection and analysis, data interpretation, 404 or writing of the report. The corresponding author had full access to all the data in the study 405 and had final responsibility for the decision to submit for publication.

406

407

408 DISCLOSURE STATEMENT. The authors have nothing to disclose.

410 AUTHOR CONTRIBUTIONS. CF and SAJ designed the study. CF, KC, SH and SAJ 411 supervised the experimental sessions. $\mathrm{CF}$ and $\mathrm{KC}$ were responsible for execution of plasma 412 analysis. $\mathrm{CF}, \mathrm{KC}$ and $\mathrm{SAJ}$ were responsible for data analysis and interpretation. $\mathrm{CF}, \mathrm{KC}, \mathrm{SH}$, 413 MDHD, $\mathrm{OH}$ and SAJ were responsible for writing and editing the manuscript. All of the 414 above-mentioned authors take full responsibility for the paper as a whole, i.e., conception and 415 design, ethics, data, analysis, and interpretation. They all approved the final version. 
417 1. WHO. Global Health Risks: Mortality and Burden of Disease Attributable to Selected Major 418 Risks. 2009. Available at: http://www.who.int/healthinfo/global_burden_disease/GlobalHealthRisks_report_full.pdf (Accessed 22 Jan 2016).

421 2. Malik VS, Willett WC, Hu FB. Global obesity: trends, risk factors and policy implications. Nat Rev Endocrinol 2013;9:13-27. doi:10.1038/nrendo.2012.199.

3. Sanchez-Lasheras C, Konner AC, Bruning JC. Front Neuroendocrinol 2010;31:4-15. doi:10.1016/j.yfrne.2009.08.002.

425 4. Schubert MM, Sabapathy S, Leveritt M, Desbrow B. Acute exercise and hormones related to appetite regulation: a meta-analysis. Sports Med 2014;44:387-403. doi:10.1007/s40279-0130120-3.

5. Hagobian TA, Sharoff CG, Braun B. Effects of short-term exercise and energy surplus on hormones related to regulation of energy balance. Metabolism 2008;57:393-8. doi:10.1016/j.metabol.2007.10.016.

431 6. Schubert MM, Desbrow B, Sabapathy S, Leveritt M. Acute exercise and subsequent energy intake. A meta-analysis. Appetite 2013;63:92-104. doi:10.1016/j.appet.2012.12.010.

433 7. Fuqua JS, Rogol AD. Neuroendocrine alterations in the exercising human: implications for energy homeostasis. Metabolism 2013;62:911-21. doi:10.1016/j.metabol.2013.01.016.

435 8. Shorten AL, Wallman KE, Guelfi KJ. Acute effect of environmental temperature during exercise on subsequent energy intake in active men. Am J Clin Nut 2009;90:1215-21. doi:10.3945/ajen.2009.28162.Am.

438 9. Wasse LK, King JA, Stensel DJ, Sunderland C. Effect of ambient temperature during acute aerobic exercise on short-term appetite, energy intake, and plasma acylated ghrelin in recreationally active males. Appl Physiol Nutr Metab $=$ Physiol Appl Nutr Metab 2013;38:905-9. doi:10.1139/apnm-2013-0008. 
442 10. Rhoads RP, Baumgard LH, Suagee J K, Sanders SR. Nutritional Interventions to Alleviate the 443 Negative Consequences of Heat Stress 1, 2 2013:267-76. doi:10.3945/an.112.003376.during.

444 11. de Lauzon B, Romon M, Deschamps V, Lafay L, Borys J-M, Karlsson J, et al. The ThreeFactor Eating Questionnaire-R18 is able to distinguish among different eating patterns in a

12. Arena R, Myers J, Williams MA., Gulati M, Kligfield P, Balady GJ, et al. Assessment of functional capacity in clinical and research settings: A scientific statement from the American Heart Association committee on exercise, rehabilitation, and prevention of the council on clinical cardiology and the council on cardiovascular n. Circulation 2007;116:329-43. doi:10.1161/CIRCULATIONAHA.106.184461.

13. Zubieta-Calleja G, Paulev P. Thermo-Regulation, Temperature and Radiation. In: New Human Physiology. $2^{\text {nd }}$ ed. Available from:

454 http://www.zuniv.net/physiology/book/chapter21.html (Accessed 22 Jan 2016).

455 14. Jay O, Bain AR, Deren TM, Sacheli M, Cramer MN. Large differences in peak oxygen uptake do not independently alter changes in core temperature and sweating during exercise. Am J Physiol Regul Integr Comp Physiol 2011;301:R832-41. doi:10.1152/ajpregu.00257.2011.

458 15. Blundell JE, De Graaf K, Finlayson G et al. Measuring food intake, hunger, satiety and 459 satiation in the laboratory. In: Allison DB, Baskin ML, ed. Handbook of Assessment Methods 460 for Eating Behaviours and Weight-Related Problems: Measures, Theory and Research. $2^{\text {nd }}$ ed. $461 \quad$ Newbury Park, California: Sage Publications. 2012. 283-325.

462 16. ANSES. Ciqual tables. 2013. Available at: https://pro.anses.fr/TableCIQUAL/ind. (Accessed $463 \quad 22$ Jan 2016).

464 17. Arvaniti K, Richard D, Tremblay A. Reproducibility of energy and macronutrient intake and related substrate oxidation rates in a buffet-type meal. Br J Nutr 2000;83:489-95. 
18. Anderson GH, Catherine NLA, Woodend DM, Wolever TMS. Inverse association between the effect of carbohydrates on blood glucose and subsequent short-term food intake in young men. Am J Clin Nutr 2002;76:1023-30.

469 19. King NA, Burley VJ, Blundell JE. Exercise-induced suppression of appetite: effects on food intake and implications for energy balance. Eur J Clin Nutr 1994;48:715-24.

471 20. Jokisch E, Coletta A, Raynor HA. Acute energy compensation and macronutrient intake following exercise in active and inactive males who are normal weight. Appetite 2012;58:7229. doi:10.1016/j.appet.2011.11.024.

21. Martins C, Truby H, Morgan LM. Short-term appetite control in response to a 6-week exercise programme in sedentary volunteers. $\quad \mathrm{Br} \quad \mathrm{J}$ Nutr 2007;98:834-42. doi:10.1017/S000711450774922X.

22. Blundell JE, Gibbons C, Caudwell P, Finlayson G, Hopkins M. Appetite control and energy balance: impact of exercise. Obes Rev 2015;16 Suppl 1:67-76. doi: 10.1111/obr.12257.

23. Moran TH. Gut peptides in the control of food intake. Int J Obes (Lond) 2009;33 Suppl 1:S710. doi:10.1038/ijo.2009.9.

481 24. Murphy KG, Bloom SR. Gut hormones in the control of appetite. Exp Physiol 2004;89:50716. doi:10.1113/expphysiol.2004.027789.

483 25. Erdmann J, Tahbaz R, Lippl F, Wagenpfeil S, Schusdziarra V. Plasma ghrelin levels during exercise - effects of intensity and duration. Regul Pept 2007;143:127-35. doi:10.1016/j.regpep.2007.05.002.

486 26. Hilsted J, Galbo H, Sonne B, Schwartz T, Fahrenkrug J, de Muckadell OB, et al. 487 Gastroenteropancreatic hormonal changes during exercise. Am J Physiol 1980;239:G136-40.

488 27. Greenberg GR, Marliss EB, Zinman B. Effect of exercise on the pancreatic polypeptide 489 response to food in man. Horm Metab Res $=$ Horm Und Stoffwechselforsch $=$ Horm Metab 1986;18:194-6. doi:10.1055/s-2007-1012268. 
491 28. Bailey DM, Davies B, Castell LM, Newsholme EA, Calam J. Physical exercise and normobaric hypoxia: independent modulators of peripheral cholecystokinin metabolism in man. J Appl Physiol 2001;90:105-13.

494 29. Hurley RS, Bossetti BM, O’Dorisio TM, Tenison EB, Welch MA, Rice RR. The effect of exercise training on body weight and peptide hormone patterns in normal weight college-age men. J Sports Med Phys Fitness 1991;31:52-6.

497 30. Hirschberg AL, Lindholm C, Carlstrom K, Von Schoultz B. Reduced serum cholecystokinin response to food intake in female athletes. Metabolism 1994;43:217-22.

499 31. Shiiya T, Ueno H, Toshinai K, Kawagoe T, Naito S, Tobina T, et al. Significant lowering of plasma ghrelin but not des-acyl ghrelin in response to acute exercise in men. Endocr $\mathrm{J}$ $2011 ; 58: 335-42$.

502 32. Dall R, Kanaley J, Hansen TK, Moller N, Christiansen JS, Hosoda H, et al. Plasma ghrelin levels during exercise in healthy subjects and in growth hormone-deficient patients. Eur $\mathbf{J}$ Endocrinol 2002;147:65-70.

505 33. Kraemer RR, Castracane VD. Exercise and humoral mediators of peripheral energy balance: ghrelin and adiponectin. Exp Biol Med (Maywood) 2007;232:184-94.

507 34. Asakawa A, Inui A, Fujimiya M, Sakamaki R, Shinfuku N, Ueta Y, et al. Stomach regulates energy balance via acylated ghrelin and desacyl ghrelin. Gut 2005;54:18-24. doi:10.1136/gut.2004.038737.

510 35. Lei L, Hepeng L, Xianlei L, Hongchao J, Hai L, Sheikhahmadi A, et al. Effects of acute heat stress on gene expression of brain-gut neuropeptides in broiler chickens. J Anim Sci

513 36. Tomasik PJ, Sztefko K, Pizon M. The effect of short-term cold and hot exposure on total plasma ghrelin concentrations in humans. Horm Metab Res $=$ Horm Und Stoffwechselforsch $=$ Horm Metab 2005;37:189-90. doi:10.1055/s-2005-861296. 
516 37. Kojima C, Sasaki H, Tsuchiya Y, Goto K. The influence of environmental temperature on 517 appetite-related hormonal responses. J Physiol Anthropol 2015;34:22. doi:10.1186/s40101$518 \quad 015-0059-1$

519 38. Van Walleghen EL, Orr JS, Gentile CL, Davy BM. Pre-meal water consumption reduces meal 520 energy intake in older but not younger subjects. Obesity (Silver Spring) 2007;15:93-9. doi:10.1038/oby.2007.506.

522 39. Rolls BJ, Bell EA, Thorwart ML. Water incorporated into a food but not served with a food decreases energy intake in lean women. Am J Clin Nutr 1999;70:448-55.

524 40. Kelly PJ, Guelfi KJ, Wallman KE, Fairchild TJ. Mild dehydration does not reduce postexercise appetite or energy intake. Med Sci Sports Exerc 2012;44:516-24. doi:10.1249/MSS.0b013e318231c176.

41. Crabtree DR, Blannin AK. Effects of exercise in the cold on ghrelin, PYY and food intake in overweight adults. Med Sci Sports Exerc 2015;47:49-57. 


\section{FIGURE CAPTIONS}

530 Figure 1. Experimental design. The subjects participated in 4 experimental sessions in

531 random order (rest at either $22^{\circ} \mathrm{C}$ or $31^{\circ} \mathrm{C}$ and exercise at $60 \%$ of their $\mathrm{VO}_{2}$ max at either $22^{\circ} \mathrm{C}$

532 or at $31^{\circ} \mathrm{C}$, all for 40 minutes). This test period was followed by a 30 -minute recovery period

533 and then an ad libitum meal. Energy balance and plasma pancreatic polypeptide (PP),

534 cholecystokinin (CCK) and ghrelin levels were determined.

Figure 2. Cardiopulmonary characteristics of the subjects over time. Mean ( \pm SEM) oxygen uptake $\left(\mathrm{VO}_{2}\right)$, heart rate and respiratory exchange ratio (RER) in each of the 4 study conditions. Some error bars are too small to appear.

a. Oxygen uptake: single effects of metabolic activity and time, and their interaction $(\mathrm{p}<0.001)$. Open triangles are overlapped by closed triangles.

b. Heart rate: single effects of metabolic activity $(p<0.001)$, temperature $(p=0.003)$ and time $(\mathrm{p}<0.001)$, and their interaction $(\mathrm{p}=0.043)$.

c. RER: single effects of metabolic activity and time, and their interaction $(\mathrm{p}<0.001)$.

545 Figure 3. Mean ( \pm SEM) visual analogic scale (VAS) score for subjective thermal comfort in 546 each of the 4 study conditions. Single effects of metabolic activity, time and temperature (all $547 \mathrm{p}<0.001)$; combined effects of metabolic activity $\mathrm{x}$ temperature $(\mathrm{p}=0.007)$, metabolic activity $548 \mathrm{x}$ time, and temperature $\mathrm{x}$ time $(\mathrm{p}<0.001)$. Metabolic activity $\mathrm{x}$ temperature $\mathrm{x}$ time interaction 549 was not significant $(\mathrm{p}=0.060)$.

551 Figure 4. Mean ( \pm SEM) relative energy intake in each of the 4 study conditions. ${ }^{*}$ Single effect 552 of metabolic activity: $\mathrm{p}=0.004$. 
554 Figure 5. Mean ( \pm SEM) composite appetite score in each of the 4 study conditions. Single 555 effect of time: $\mathrm{p}<0.001$.

557 Figure 6. Mean ( \pm SEM) plasma pancreatic polypeptide (PP) in each of the 4 study 558 conditions. Single effects of metabolic activity: $p=0.002$ (ex $>$ rest) and time: $p<0.001$ $559 \quad(\mathrm{~T} 100>\mathrm{T} 0, \mathrm{~T} 40, \mathrm{~T} 55)$.

560

561 Figure 7. Mean ( \pm SEM) plasma cholecystokinin (CCK) in each of the 4 study conditions. 562 Single effect of time: $\mathrm{p}=0.005(\mathrm{~T} 100>\mathrm{T} 40, \mathrm{~T} 55)$ and combined effects of metabolic activity $563 \mathrm{x}$ time: $\mathrm{p}=0.005$. Post-hoc analysis: in the rest $-22^{\circ} \mathrm{C}$ condition: ${ }^{*} \mathrm{~T} 100$ significantly different 564 from $\mathrm{T} 55(\mathrm{p}=0.006)$; in the rest- $31^{\circ} \mathrm{C}$ condition: \# T100 significantly different from $\mathrm{T} 0$, T40 565 and T55 $(\mathrm{p}<0.001)$.

567 Figure 8. Mean ( \pm SEM) plasma ghrelin in each of the 4 study conditions. Single effect of 568 temperature: $\mathrm{p}=0.031\left(22^{\circ} \mathrm{C}>31^{\circ} \mathrm{C}\right)$. 


\begin{tabular}{|c|c|c|c|c|}
\hline & sed-22 ${ }^{\circ} \mathrm{C}$ & sed-31 ${ }^{\circ} \mathrm{C}$ & $\mathrm{ex}-22^{\circ} \mathrm{C}$ & ex-31 ${ }^{\circ} \mathrm{C}$ \\
\hline Water intake during the 40 min-test (g) & $(51 \pm 63$ & $116 \pm 74)^{* *}$ & $(164 \pm 76$ & $287 \pm 87)$ \\
\hline Water intake to compensate hydric loss (g) & $(30 \pm 95$ & $10 \pm 32) *$ & $(180 \pm 193$ & $354 \pm 259)$ \\
\hline Water intake during the meal (g) & $277 \pm 29$ & $278 \pm 29$ & $256 \pm 88$ & $259 \pm 64$ \\
\hline Total water intake (g) & $(359 \pm 104$ & $403 \pm 80)^{* *}$ & $(600 \pm 218$ & $900 \pm 238)$ \\
\hline
\end{tabular}

$*$ : single effect of metabolic activity with $\mathrm{p}<0.01 ; * *$ : single effect of metabolic activity with $\mathrm{p}<0.001$; \#: single effect of temperature with $\mathrm{p}<0.05$; \#\#: single effect of temperature with $\mathrm{p}<0.001$. 